Paidéia, 2001, 11(20), 67-77

\title{
EDUCAÇÃo, DIREITOS HUMANOS, TOLERÂNCIA e PAZ ${ }^{1}$
}

\author{
Roseli Fischmann ${ }^{2}$ \\ Universidade de São Paulo
}

\begin{abstract}
RESUMO: Este artigo pontua os dados históricos da criação da ONU e posteriormente a elaboração da Declaração Universal dos Direitos Humanos, salientando que uma tem a face social e a outra focaliza o indivíduo. Discute a seguir a percepção da injustiça e as formas de se opor a ela, de resistência à opressão, a escolha pela ONU de 1995 como Ano Internacional da Tolerância diante da realidade de muitos conflitos étnicos e religiosos espalhados pelo mundo, para embasar a argumentação da necessidade de cooperação dos meios de comunicação, da escola, da ação responsável do Estado ao assumirem a defesa dos princípios da Tolerância. No final há a proposta de uma metodologia de trabalho para uma educação que desenvolva o sentido de respeito aos Direitos Humanos e à Tolerância entre os povos.
\end{abstract}

Palavras-chave: Direitos Humanos; Princípios da Tolerância; Educação para a Paz

\section{EDUCATION, HUMAN RIGHTS, TOLERANCE AND PEACE}

ABSTRACT: This article brings historical data about ONU creation and the Universal Declaration of Human Rights, emphasizing the social face of the first and the individual predominance of the second. It is discussed the perception of injustice and the ways to oppose to it, the resistance to oppression, the choice made by ONU of 1995 as the International Year of Tolerance because the many ethnic and religious conflicts all over the world, to argument in favor of mass media, school and State action cooperation in defense of Tolerance principles. To conclude, there exist the proposition of a work methodology to afford an education able to develop the respect to Human Rights and Tolerance between the nations

Key words: Human Rights; Principles of Tolerance; To educate for peace

"Guardar uma coisa é vigiá-la, isto é, fazer vigília por ela, isto é, velar por ela, isto é, estar acordado por ela, isto é, estar por ela ou ser por ela.

Por isso melhor se guarda o vôo de um pássaro

Do que um pássaro sem vôos"

Antonio Cícero - "Guardar"

O Século XX legou à humanidade, como acontecimentos terríveis, a barbárie do Holocausto e o horror de Hiroshima e Nagasaki. Duas faces da mesma moeda - o conflito que agitava o planeta naquele momento - são a mostra de como a humanidade pode gerar a autodestruição, sobretudo valendose do trabalho científico e de seus produtos. Vindo

\footnotetext{
${ }^{1}$ Artigo recebido para publicação em dezembro de 2001; aceito em fevereiro de 2002

${ }^{2}$ Endereço para correspondência: Roseli Fischmann, Programa de PósGraduação em Educação da Faculdade de Educação da Universidade de São Paulo. E-mail: roseli.fischmann@uol.com
}

de um longo caminho histórico de busca de construção de um organismo mediador do entendimento entre diferentes países, a criação da Organização das Nações Unidas, em 1945, expressou, com a Carta de São Francisco, o reconhecimento da dependência mútua e da necessidade impostergável de uma ação conjunta de diferentes povos. Na seqüência, a proclamação, em 10 de dezembro de 1948, pela Assembléia Geral da ONU, em Nova York, da Declaração Universal dos Direitos Humanos (DUDH) foi mais um gesto na mesma direção.

Vale, contudo, observar a dinâmica histórica presente na delicada construção de entrelaçamento dos dois eventos, por intermédio da diferenciação e complementaridade dos focos. Se a criação da ONU destacava a importância de proteger os Estados, a DUDH explicitava o reconhecimento do caráter insubstituível de cada indivíduo para a espécie humana. Na ONU, a disposição para a negociação, ine- 
vitável para a atuação coletiva fundada no respeito e ação em concerto ${ }^{3}$. Na Declaração, a intransigência na proteção dos direitos fundamentais de todo e cada ser humano. Em ambas, a intenção de construção de uma herança universal para a humanidade.

Contudo, no tão esperado início do Século $\mathrm{XXI}$, começo de século e milênio, a humanidade deparou-se com a perplexidade do 11 de setembro, data transformada em substantivo. Se é certo que há muito estudo ainda por se fazer em relação ao tema, gesto de terrorismo a ser para sempre repudiado, é também inegável que ali se expressou o máximo do tensionamento que seria possível haver entre duas cosmovisões. É a visão de um Outro que se apresenta tão inapreensível e tão irredutível ao que se conhece, que provoca o gesto de anulação. Mais ainda, já se anunciava no horizonte, havia tempos, o questionamento do universal proposto na DUDH, de múltiplas formas.

Em artigo célebre, publicado na revista Foreign Affairs, Samuel Huttington já tratava, no início dos anos 90, do que chamou "Choque de Civilizações" gerando, no final da mesma década, a proposta, feita pelo presidente do Irã, de que 2001 fosse proclamado como o Ano Internacional do Diálogo de Civilizações, buscando responder à análise de Huttington, afirmando que o choque da civilização ocidental com o mundo islâmico seria inevitável.

A própria divisão sumária em dois "blocos", Ocidente e Oriente, é insatisfatória, expressando, de fato, mais a busca do estabelecimento de alguma alteridade, pela civilização ocidental, ainda que ilusória, do que o reconhecimento dos que vivem, adotando outras culturas. Com a dinâmica dos movimentos populacionais, a diversidade cultural não pode ser aprisionada sequer em regiões específicas, seja quando se considera questões regionais, no âmbito nacional, seja na relação entre povos e nações.

No interior do que se tenta reduzir a "Oriente", por exemplo, há a convivência de tradições asiáticas distintas entre si, como o hinduísmo e o taoísmo, ou como o budismo e o islamismo. A análise de Huttington, longe de ser simplificadora, não reduziu o Oriente a um adjetivo único, mas chamou a atenção para o novo tipo de fronteira que começava a se explicitar pelo mundo - e que não se restrin-

\footnotetext{
${ }^{3}$ No sentido proposto por Hannah Arendt.
}

ge, em absoluto, à geopolítica.

Edward Said (1990) já chamara a atenção para a importância de analisar criticamente estudos que "criam" um Oriente, não à sua imagem e semelhança, mas, ao contrário, pelo mecanismo de espelho, transformam a mera inversão, simulacro de alteridade, em suposta realidade indiscutível, aprisionando o Outro dentro dos limites dados por essa invenção.

Assim, a temática das singularidades de povos e nações infiltra-se no debate internacional, fazendo com que, antes mesmo de ter havido a disseminação tanto do teor da DUDH, quanto - e sobretudo - de sua aplicação, se efetive o questionamento do sentido do universal ali presente. Nesse caso, a compatibilização entre o singular e o universal, no campo internacional, tem se apresentado como o grande tema.

É inevitável a aplicação da temática para as relações interpessoais, expressando-se, aí, a questão da singularidade da pessoa, as composições da diversidade, internas aos grupos, assim como sentimentos de pertinência e identificação de raízes, gerando uma rede múltipla de referências pessoais, indissoluvelmente ligada à própria construção da identidade (Fischmann, 1996). Nesse sentido, há um significado

presente

na

DUDH que dignifica o campo jurídico, pelo que permite garantir de respeito ao ser humano, quanto às liberdades fundamentais e à prática de deveres.

Juntamente com a complexidade inerente à elaboração da relação entre o universal, considerando a humanidade, e singularidades, referentes sobretudo à diversidade cultural, coloca-se como temática central, para o novo século, a equivalente complexidade de elaboração da relação entre o homem como sujeito de seu ser, isto é, a vivência da autonomia, e a definição da ordem jurídica, a ser experienciada não como prática de heteronomia, mas como construção de autonomias individuais, entrelaçadas e interdependentes.

Assim, por exemplo, Moore Jr.(1987), em seu livro, lembra que é necessário haver normas básicas, que sobrevivam à necessidade de a sociedade estar refazendo a cada vez seu contrato social. A obediência a tais normas constitui-se, nesse caso, em um gesto de maturidade, pela adesão aos valores da sociedade 
específica em que se vive. Haveria, aqui, incluídas na normatização e no contrato, formas de coerção social previstas, assim como de punição, consideradas por todos como justas.

Por outro lado, existem alguns elementos, como a opressão e a injustiça, que, uma vez surgidos, podem significar uma ruptura do contrato social, frente à qual é próprio da maturidade não mais obedecer, mas resistir. Moore Jr destaca, então, que o perigo está nas sociedades onde se encontraram formas de controlar toda resistência, onde a injustiça é vista como inevitável, e portanto, sufoca-se na base toda indignação e ira moral geradas pelo sentimento de injustiça.

É sobretudo frente a ordens injustas ou opressivas que se revelam a autonomia moral e a coragem moral. Barrington Moore Jr identifica três qualidades da autonomia moral:

\begin{abstract}
"A primeira qualidade pode ser chamada de coragem moral, no sentido de uma capacidade de resistir a poderosas e ameaçadoras pressões sociais para a obediência a regras ou ordens 'opressivas' ou 'destrutivas'. A segunda qualidade é a capacidade intelectual para reconhecer que as regras $e$ as pressões são de fato opressivas. (...). A terceira capacidade, a inventividade moral, é mais rara (...)..$E$ a capacidade de criar, a partir das tradições culturais vigentes, padrões historicamente novos de condenação ao que existe." (Moore $J r, 1987, p .136-137)$
\end{abstract}

Tratando dos efeitos do poder de pressão do grupo sobre o julgamento expresso por um indivíduo, com base em experimentos de Asch, Moore Jr (1987) enfatiza que "um único aliado pode fornecer suficiente apoio para capacitar uma pessoa a elaborar um julgamento correto"4 (p.139). A mesma conclusão resultou do famoso experimento de Stanley Milgran, envolvendo cobaias humanas pseudo-submetidas a choques por ordem de pseudoexperimentadores a agentes que demonstraram sua capacidade de resistir a ordens cruéis, ou, ao contrá-

\footnotetext{
' Moore Jr enfatiza, na seqüência de sua argumentação, que há boas razōes para se considerar que o inverso também ocorra, ou seja, que basta um único apoio para que um julgamento incorreto seja consolidado.
}

rio, de extrapolá-las. Nesse experimento, a oferta de apoio social foi a mais eficaz variante no solapamento da autoridade cruel e sádica do "experimentador".

Entre outras conclusões do longo e denso estudo de Barrington Moore Jr., a capacidade de identificar a opressão e a injustiça são tratadas como sendo centrais na busca da construção de uma situação social mais justa a cada vez. Da mesma forma, o desenvolvimento do sentido de inevitabilidade como ilusório - ou seja, a compreensão de que há certas condições desumanas, dolorosas ou degradantes de que não se necessita, não se pode e não se deve suportar.

A reversão do sentido de inevitabilidade significa que as pessoas possam compreender que a dificuldade na alteração de certa situação dolorosa vigente não implica em que a mesma integre a ordem "natural" das coisas, sendo por isso inevitável, mas que essa dificuldade talvez diga respeito a outras tantas, como tradições arraigadas ou interesses, que não a melhoria da qualidade da vida humana.

Nesses processos pelos quais se desenvolve a capacidade de identificação da opressão e da injustiça, e de solapamento do sentido de inevitabilidade, a informação desempenha um papel crucial, assim como o debate aberto e esclarecido (Adorno \& Horkheimer, 1985), que sirva como apoio social, capaz de fortalecer o discernimento facilitador do sentimento de injustiça, dando suporte à resistência.

Neste ponto evidencia-se a relevância da escola e de atividades ligadas à educação informal nas quais poderíamos incluir a ação das mídias impressas em papel e eletrônicas - seja como favorecedora de informação, seja como facilitadora de processos que conduzam à formação da capacidade crítica, bem como de habilidades de expressão de opinião e, sobretudo, de resistência à opressão. ${ }^{5}$

\section{Diversidade e tolerância}

Em 1993, a Assembléia Geral da ONU decidiu que 1995, quando se comemoraria seu cinqüentenário, seria o Ano Internacional da Tolerância. A decisão vinculava-se ao reconhecimento

\footnotetext{
"Apenas para citar alguns autores que têm lidado com a temática, além de Paulo Freire e teóricos que vêm partilhando de seu pensamento, convém lembrar Michael Apple, Henry Giroux, autores exemplificativos dessa preocupação na educação.
} 
humilde e apropriado de que, cinqüenta anos após sua criação, a Organização das Nações Unidas se encontrava longe de atingir o objetivo para o qual havia sido criada, ou seja, o de alcançar a paz mundial. No contexto da época, a Guerra da Bósnia e conflitos étnicos na África, além de diversos outros pontos conflagrados no planeta, principalmente por motivos de intolerância étnica e religiosa, faziam constatar que seria necessário, meio século depois, pensar ainda o primeiro passo, o mais básico, que, embora inicial, e tardiamente, traz, em si, o todo da jornada.

Ao longo de 1994 e 1995 foram realizados diversos encontros regionais preparatórios, sob patrocínio da Unesco, escolhida como responsável pelo evento, tendo sido criada a Unidade da Tolerância na sede da organização, em Paris. Tais encontros discutiam o conceito "tolerância", tendo em conta as diversas realidades regionais. Culminaram com a elaboração e a aprovação, pela Conferência Geral da Unesco, em 16 de novembro de 1995, da Declaração Mundial de Princípios sobre a Tolerância.

No Brasil, a Unesco promoveu, em âmbito preparatório, em 1994, o Encontro sobre Tolerância na América Latina e Caribe, em cooperação com a UFRJ, e, em 1997, o Seminário Internacional Ciência, Cientistas e a Tolerância, em cooperação com a USP, do qual resultou a criação da Rede Unesco das Américas e Caribe para a Tolerância e a Solidariedade, com amplo apoio de órgãos governamentais, não-governamentais, agências financiadoras e mídia. A rede de escolas associadas da Unesco, no Brasil, também tem se mobilizado, ao longo dos anos, para promover o 16 de novembro no ensino fundamental e médio.

Desde a época daqueles debates regionais, a adoção do termo "tolerância" foi, muitas vezes, duramente criticada. Houve quem lembrasse que seria até indesejável "ser tolerado", quando o mínimo que se espera é ser respeitado. Contudo, o conceito de tolerância, como mobilizador de consciências, não pode ser confundido com seu uso trivial. Vale transcrever o artigo primeiro da Declaração: "A tolerância é o respeito, a aceitação e o apreço da riqueza e da diversidade das culturas de nosso mundo, de nossos modos de expressão e de nossas maneiras de exprimir nossa qualidade de seres humanos. É fomen- tada pelo conhecimento, abertura de espírito, a comunicação e a liberdade de pensamento, de consciência e de crença. A tolerância é harmonia na diferença. Não só é um dever de ordem ética; é igualmente uma necessidade política e de justiça. A tolerância é uma virtude que torna a paz possível e contribui para substituir uma cultura de guerra por uma cultura de paz".

A declaração trata do papel do Estado, da educação, da sociedade, dos meios de comunicação. Apresenta-se, sempre, de maneira central, a perspectiva do pleno respeito aos direitos universais e às liberdades fundamentais de todos, como base da construção da paz. Voltando-se para a temática dos riscos da intolerância, a declaração afirma, no artigo $4^{\circ}$, que "a educação para a tolerância deve visar a contrariar as influências que levam ao medo e à exclusão do outro e deve ajudar os jovens a desenvolver sua capacidade de exercer um juízo autônomo, de realizar uma reflexão crítica e de raciocinar em termos éticos".

O sentido de educar para a tolerância e de praticar a tolerância está também aí: conhecer o outro, todos os outros, que vivem de forma distinta daquela que conhecemos. Apenas o conhecimento pode levar à superação do medo que gera preconceito e discriminação. Por isso, o sentido da tolerância é o da valorização da diversidade humana e o da busca de viver com o outro de forma respeitosa, saudável, pautando a resolução de problemas e desacordos pela via do diálogo.

Da mesma forma, falar em respeito é falar de como é inaceitável a miséria, a injustiça da desigualdade, que não se confunde com a diversidade. Por isso, falar de tolerância é falar também do intolerável: a violação de direitos, a injustiça, a desigualdade, as muitas faces da violência.

Tomando a Declaração, aprovada pela Conferência Geral da Unesco, a tolerância é compreendida como um princípio e uma virtude "que torna a paz possível e contribui para substituir uma cultura de guerra por uma cultura de paz". Invocando documentos anteriormente aprovados pelas Nações Unidas, a Declaração engloba o respeito à liberdade de pensamento e de crença, assim como à diversidade de aparência física, de modo de expressar-se, de comportamento e de valores. Tudo, no sentido de que os 
seres humanos "têm o direito de viver em paz e de ser tais como são" e (...), também, "que ninguém deve impor suas opiniões a outrem".

Em consonância com a proposta presente nos documentos da ONU, afirma-se, ali, que sem tolerância não há paz e sem paz não há desenvolvimento nem democracia. Podemos acrescentar um indispensável "e vice-versa", que se manifesta na Declaração em afirmações como "a exclusão e a marginalização podem conduzir à frustração, à hostilidade e ao fanatismo". Assevera, ainda, a importância do respeito aos direitos humanos como forma de "garantir igualdade de tratamento e de oportunidades aos diferentes grupos e indivíduos da sociedade".

Relembrando que não há sob a face da terra grupo humano que não seja marcado pela diversidade, mesmo a interna, alertava, em 1995, que "a intensificação da intolerância e dos confrontos constituí ameaça potencial para cada região", não se tratando, pois, "de ameaça limitada a esse ou aquele país, mas de ameaça universal".

Contudo, entre as incompreensões que sofre o conceito, encontra-se a de que a tolerância tenderia a gerar uma sociedade que permitiria a expansão da própria barbárie, em nome do respeito à diferença. Ora, não pode haver equívoco maior. A tolerância "não é concessão, condescendência, indulgência", afirma a Declaração, e praticá-la "não significa tolerar a injustiça social, nem renunciar às próprias convicções, nem fazer concessões a respeito".

Um importante subsídio para o aprofundamento do tema é dado pelo indispensável estudo "As razões da tolerância", de Bobbio (1992). Trata-se de reflexão que demonstra a dificuldade de se lidar com o conceito, e como, do ponto de vista ético, é inevitável a adesão à prática. Metodologicamente, compara a tolerância com a intolerância. Afirma que o tolerante acusa o intolerante de fanático, que o acusa de ser um cético ou pelo menos um indiferente, se entendesse não existir verdade pela qual valeria a pena lutar. Bobbio refuta a posição, dizendo que o binômio intolerância-tolerância não encontra correspondência no binômio fanatismo-indiferença, que não seria exatamente formado por oposição. Tira daí o ponto de partida para falar das boas razões da tolerância.
A primeira é que "a verdade tem tudo a ganhar quando suporta o erro alheio" - opinião a ser revista em cada caso concreto, relembra, por prudência política. O mais forte pode ser tolerante por ser astuto, procurando não perseguir, para não ver crescer a posição de que e de quem discorda, pelo escândalo da perseguição. Por outro lado, o mais fraco pode ser tolerante por necessidade, já que a rebelião pode levar ao esmagamento do fragilizado. Se somos iguais, é por reciprocidade, base de todos os compromissos. Aqui, portanto, tolerância é um problema de cálculo, nada a ver com a verdade.

A segunda boa razão que Bobbio apresenta refere-se a que seria método universal de convivência civil. Seria utilizada a persuasão, ao invés da força e da coerção, praticada a confiança na capacidade alheia de entender o bem comum, e a "recusa consciente da violência como único meio para obter o triunfo das próprias idéias". Aqui, portanto, trata-se de uma questão de método, onde a argumentação, na retórica, tem relação direta com o método democrático, na prática.

A terceira boa razão seria entendida como princípio moral absoluto, dever ético, em que o respeito à pessoa alheia é profundamente ligado aos direitos de liberdade, aos direitos naturais ou invioláveis.

Ora, da segunda e da terceira razão depreendese a íntima ligação da temática da tolerância com o Estado liberal e o Estado democrático. Ao mesmo tempo, do ponto de vista da teoria, a aceitação da tolerância como princípio coloca a afirmação de que a verdade só pode ser alcançada pelo confronto de opiniões, uma vez que nenhuma, isoladamente, daria conta dela; haveria sempre, pois, necessidade da síntese de diferentes visões. Trata-se, nas palavras de Bobbio, não de universo, mas de "multiverso". Daí a tolerância apresenta-se como necessidade inerente à natureza da verdade.

Aqui é o ponto em que Bobbio, como a Declaração, trata das boas razões da intolerância, que se manifesta sempre que há a imperiosa necessidade de dizer "é intolerável que...". Lembra o filósofo que, se em seu sentido positivo "é sinônimo de severidade, rigor, firmeza", tolerância em sentido negativo, ao contrário, "é sinônimo de indulgência culposa, de condescendência com o mal, com o erro, por falta de 
princípios, por amor da vida tranqüila, ou por cegueira diante dos valores". Portanto, destacando um sentido positivo e um negativo, tanto para tolerância como para intolerância, Bobbio ressalta que a tolerância absoluta é uma abstração. Que a tolerância histórica sempre é relativa, que há uma "zona cinzenta" de "nem isso nem aquilo", já que a história é ambígua.

A Declaração de Princípios sobre a Tolerância traz a mensagem da urgência de trabalharmos sobre nós mesmos, de cooperação dos meios de comunicação e da escola, da ação responsável do Estado. Afirma que "a educação para a tolerância deve visar a contrariar as influências que levam ao medo e à exclusão do outro e deve ajudar os jovens a desenvolver sua capacidade de exercer um juízo autônomo, de realizar uma reflexão crítica e de raciocinar em termos éticos". Não se trata de tarefa simples, mas é possível e, mais que nunca, inadiável. Exercer e exercitar a reflexão crítica, assim como o respeito ao outro, não é mera retórica, mas, sim, questão de sobrevivência da própria espécie humana ${ }^{6}$.

Uma proposta metodológica de Educação para Direitos Humanos, Tolerância e Paz

Considerando que a defesa dos Direitos $\mathrm{Hu}$ manos exige o conhecimento do teor de sua Declaração Universal, e que tal conhecimento deve se realizar pela reflexão e pela sensibilidade, desenvolvemos uma metodologia de educação para direitos humanos, pioneira em nível mundial, que teve um de seus frutos em publicação do Ministério da Justiça, em 1998, ocasião da celebração dos Cinquientenário de Promulgação da DUDH.

Ao coordenar a elaboração do Manual Direitos Humanos no Cotidiano, da Secretaria Nacional dos Direitos Humanos, Unesco e USP, a pedido do então Ministro da Justiça, José Gregori, efetivamos cada um dos artigos da Declaração como um capítulo, formado por diversas seções: O Olhar de, A Palavra de, a Experiência e a Contribuição de, Aspectos Jurídicos, A Tradução Indígena, O que Podemos Fazer desde já

\footnotetext{
" A Declaração dos Princípios da Tolerância foi traduzida para o português por Odete Medauar, no marco do Seminário Internacional Ciência, Cientistas e a Tolerância, 1997.
}

Na seção "O Olhar de" estiveram presentes cerca de trinta e cinco artistas. Sensibilidade e estética têm papel específico e indispensável a desempenhar na transformação da sociedade e do ser humano. Esse entendimento reafirma-se no tratamento iconográfico do Manual, visibilizando trabalhos desenvolvidos por indivíduos e organizações da sociedade civil, lembrando que a luta em prol dos direitos humanos é antiga em nosso país.

Na seção "A Palavra de", encontram-se cerca de sessenta pessoas: homens e mulheres, jovens e idosos, religiosos e ateus, afro-descendentes, indígenas, orientais, judeus, árabes, federação de indústrias e sindicalistas, vivendo na prática a diversidade étno-racial, cultural, religiosa que há no Brasil; uma personalidade faz um comentário, um poema, dá um testemunho de vida. "Personalidade" é quem faz algo por nosso país e pela humanidade, mesmo que os holofotes da fama não estejam sobre seu rosto - todos têm algo a dizer sobre os direitos humanos universais, já que se trata da possibilidade da reconstrução da vida e do ser humano.

Na seção "A Experiência e a Contribuição de", foram incluídas sessenta organizações não-governamentais, fundações e institutos da sociedade civil. Retomamos aqui a idéia de que há muito trabalho já desenvolvido, que o campo é vasto e tem sido abordado de maneira fértil - e que existem alternativas para as mais diversas vocações sociais.

A seção "Aspectos Jurídicos" apresenta um estudo detalhado dos instrumentos jurídicos nacionais e internacionais que um cidadão pode invocar para proteger seus direitos e conhecer seus deveres. Foi cuidadosamente preparada por equipe de pesquisa formada por profissionais e acadêmicos da área jurídica, coordenados por Anna Cândida da Cunha Ferraz, professora da Faculdade de Direito da Universidade de São Paulo, que desenvolveu metodologia própria de levantamento e análise de documentos jurídicos para aplicação nesse Manual.

A seção "a Tradução Indígena" foi inserida como forma de, por intermédio do texto preparado para cada um dos artigos por Marcos Terena, liderança indígena histórica, com o que buscávamos prestar homenagem aos habitantes imemoriais de nossa terra, explicitar, uma vez mais, o pleno reconhecimento ao direito de voz de cada grupo humano, as- 
sim como o de que a principal fonte de autoridade sobre cada grupo humano encontra-se, antes de tudo, nos integrantes do próprio grupo, individual e coletivamente.

A seção "O que Podemos Fazer desde já?", traz sugestões que todos podem efetivar. É preciso disseminar a compreensão de que a Declaração Universal dos Direitos Humanos trata do que é básico para toda pessoa. Dignidade humana, liberdade e justiça, direito de defesa, direito à educação, à moradia, à saúde, ao desenvolvimento, ao trabalho, a salários dignos, ao lazer, à liberdade de consciência, de opinião e de crença, à liberdade de associação, à nacionalidade, a ir e vir, à privacidade, ao acesso aos bens culturais que são patrimônio da humanidade e de seu grupo específico, a ser respeitado independentemente de sexo, raça/etnia, classe social, idade, religião, origem social, enfim, sem discriminação de qualquer tipo que o exclua; a não ser escravizado, a não ser torturado, a todos direitos e condições que permitam que o mais básico, o direito à vida, possa ser vivido com dignidade, participando da construção da sociedade a que pertence.

Observe-se que essa metodologia funda-se em pressupostos que têm guiado nosso trabalho e que ganharam elaboração acadêmica, como metodologia, por volta de $1990^{7}$. Trata-se de reafirmar, a cada trabalho, que, lembrando Levinas "a ética, 'já por si mesma', é uma óptica”. Em meu credo de pesquisadora completo: "a ética é uma óptica", instaura a conduta, define a direção metodológica.

Afirmávamos, em artigo anterior (1998a), que o que se propõe é:

"(...) um trabalho que compõe pesquisa e intervenção educacional. É Levinas que nos traz à reflexão a certeza de que o contato com o Outro e a busca do Absolutamente Outro é o verdadeiro ensino. Assim, que melhor tema haveria para uma intervenção educacional que a busca da compreensão objetiva de como se dá a negação do Outro pelo preconceito, pela discriminação, pela estigmatização? Ora, trata-se de estudar, investigar, aprender e apre-

\footnotetext{
${ }^{7}$ Ver, a esse respeito Fischmann, R, in http://www.mre.gov.br/ipri/ SDIREITOSHUMANOS), onde são explicitados os pressupostos metodológicos de nosso trabalho.

${ }^{1}$ Artigo recebido para publicação em dezembro de 2000; aceito em junho de 2001
}

ender, em um processo que, ao mesmo tempo que identifica o problema, busca alternativas para sua superação. Nesse sentido não pode ser uma atividade solitária, mas sim solidária, tratando-se de indispensável integração entre ações teóricas e ações práticas, em uma dinâmica de revezamentos (p.69-70)

Ao lidar com temas do cotidiano, onde há um conhecimento vulgar estabelecido, trata-se também de superar obstáculos epistemológicos arraigados, entre outros motivos, por inércia do espírito, pela valorização indevida de idéias, o que acaba por se opor à circulação de valores, onde "aquilo que se julga saber claramente ofusca aquilo que se deveria saber" (Bachelard, 1984, p.166).

A proposta, então, é a participação de representantes de movimentos e organizações étnicas e de minorias religiosas, em interação com o mundo acadêmico, como um investimento na possibilidade de rediscussão das fontes de autoridade na construção do saber sobre etnias, ao mesmo tempo em que se tecem novas relações da prática com a teoria.

Foi com base nessa proposta, que o Manual Direitos Humanos no Cotidiano expressou a rica diversidade etno-cultural-religiosa- racial brasileira, no que tem de mais criativo e ativo, em face da cidadania. É obra de integração teoria e prática, de busca de integração entre coletivo e individual, assim como resultado da busca da plena expressão, na vida cotidiana, do que estabelece a DUDH.

\section{Mirando a paz}

A importância da reflexão sobre a temática dos direitos humanos e da tolerância é que, como bem indicado em diversos livros, declarações e outros documentos da UNESCO, vincula-se às bases da própria possibilidade da construção e manutenção da paz - e portanto, como já está plenamente assimilado pela consciência de todos, à própria sobrevivência da humanidade.

Nas premissas da DUDH, não se pode falar 


\section{Roseli Fischmann}

em paz aqui ou ali, senão em paz para a humanidade como um todo. Enquanto houver um ser humano entregue à miséria, ou ao medo, o mundo não conhecerá a paz. Em seu ensaio Sobre a Violência, Arendt (1996) afirma que a violência, em todas suas manifestações, coloca-se como instrumental, procurando justificar-se pelos fins que almeja. Aí se inclui a guerra, mais uma forma de violência que, necessitando justificar-se por outra coisa, que não ela mesma - no caso, a vitória de princípios ou valores, ou a própria paz - não é essência de coisa alguma. Já com relação à paz, não se pergunta qual seu fim, não se busca justificativa. Por isso, afirma Arendt, "a paz é um absoluto, mesmo se na história os períodos de guerra quase sempre superaram os períodos de paz". Vale a pena atentar para a distinção que faz entre poder e violência. $O$ poder, como inerente onde as pessoas se unem e agem em concerto, legitima-se no passado, no momento inaugural da decisão da vida conjunta. Já a justificação remete ao futuro, aos fins.

Ora, continua a pensadora, "a justificação perde em plausibilidade quanto mais o fim almejado distancia-se no futuro". O poder sempre emerge da decisão coletiva de agir junto. Num confronto, a violência pode vencer o poder, sobretudo por causa dos artefatos de que pode dispor, mas denuncia sua fraqueza. Quanto mais violência para vencer, mais certo o resultado, de que o poder será mais certamente destruído, resultando na mera dominação de um ser humano sobre outro.

A paz, assim, não é um estado letárgico, ou a renúncia ao poder, mas a expressão mais viva e vigorosa do real poder, o que se articula como decisão e ato de vontade, de quem deseja construir. Por isso, o fortalecimento do ser humano, individual e coletivamente - o que inclui, como tratado por Moore-Jr, a capacidade de se indignar e de resistir contra injustiças - conta com a Declaração Universal dos Direitos Humanos como instrumento, como agenda comum da humanidade. Este ensaio, reflexão de educadora, coloca-se modestamente como contribuição à discussão e difusão, desse que é, por enquanto, o melhor instrumento de reconhecimento universal que a humanidade criou para si.

\section{Referências Bibliográficas}

Adorno, T. \& Horkheimer, M. (1985). Dialética do esclarecimento, $2^{a}$ ed.. Rio de Janeiro: Jorge Zahar.

Arendt, H. (1996). Sobre a Violência. Rio de Janeiro: Relume Dumará.

Bachelard, G. (1984). A epistemologia. Lisboa: Edições 70.

Bobbio, N.(1992). A era dos direitos. Rio de Janeiro: Editora Campus.

Fischmann, R.(1996). "Educação, Democracia e a Questão dos Valores Culturais", in K. Munanga (org.) Estratégias e Políticas de Combate ao Racismo (p. 177-194), São Paulo: EDUSP/Estação Ciência.

Fischmann, R. (1998a) "Estratégias de superação da discriminação étnica e religiosa no Brasil". $D i$ reitos humanos no Século XXI. Parte II. Brasília: MRE/IPRI/FUNAG, p. 959-985.

Fischmann, R (1998b) Manual Direitos Humanos no Cotidiano. Brasília: Ministério da Justiça/ UNESCO/USP.

Foucault, M. (1984). Microfísica do poder, $4^{\mathrm{a}}$. ed., Rio de Janeiro: Graal.

Huttington, S. (1994). Politica Externa. Rio de Janeiro: Paz e Terra.

Moore-Jr., B. (1987). Injustiça - as bases sociais da obediência e da revolta. São Paulo: Brasiliense.

ONU (1948). Declaração Universal dos Direitos Humanos.

UNESCO (1995). Declaração Mundial de Princípios sobre a Tolerância

Said, E. (1990) Orientalismo - O Oriente como invenção do Ocidente. São Paulo: Companhia das Letras. 


\section{Anexo}

\section{Declaração Universal dos Direitos Humanos}

\section{Preâmbulo}

Considerando que o reconhecimento da dignidade inerente a todos os membros da família humana e de seus direitos iguais e inalienáveis é o fundamento da liberdade, da justiça e da paz no mundo,

Considerando que o desprezo e o desrespeito pelos direitos humanos resultaram em atos bárbaros que ultrajaram a consciência da humanidade e que foi proclamado, como a mais alta aspiração do homem comum, $o$ advento de um mundo em que os seres humanos, livres do medo e da miséria, gozem da liberdade de palavra e da liberdade de crenças,

Considerando essencial que os direitos humanos sejam protegidos pelo Estado de Direito, para que o homem não seja compelido, como último recurso, à rebelião contra a tirania e a opressão,

Considerando essencial promover o desenvolvimento de relações amistosas entre as nações,

Considerando que os povos das Nações Unidas reafirmaram, na carta, sua fé nos direitos humanos fundamentais, na dignidade e no valor da pessoa humana e na igualdade de direitos dos homens e das mulheres, e que decidiram promover o progresso social e melhores condições de vida em uma liberdade mais ampla,

Considerando que os Estados-membros se comprometeram a promover, em cooperação com as Nações Unidas, o respeito universal aos direitos humanos e liberdades fundamentais e a observância desses direitos e liberdades,

Considerando que uma compreensão comum desses direitos e liberdades é da mais alta importância para o pleno cumprimento desse compromisso,

\section{A Assembléia Geral proclama a presente Declaração Universal dos Direitos Humanos}

Como o ideal comum a ser atingido por todos os povos e todas as nações, com o objetivo de que cada indivíduo e cada órgão da sociedade, tendo sempre em mente esta Declaração, se esforce, através do ensino e da educação, por promover o respeito a esses direitos e liberdades, e, pela adoção de medidas progressivas de caráter nacional e internacional, por assegurar o seu reconhecimento e a sua observância universais e efetivos, tanto entre os povos dos próprios Estados-membros, quanto entre os povos dos territórios sob sua jurisdição.

Artigo $1^{\circ}$-Todos os seres humanos nascem livres e iguais em dignidade e direitos. São dotados de razão e consciência, por isso devem agir fraternalmente uns com os outros.

Artigo $2^{\circ}$ 1- Toda pessoa tem capacidade para gozar os direitos e as liberdades estabelecidos nesta Declaração, sem distinção de qualquer espécie, seja raça, cor, sexo, língua, religião, opinião política ou de outra natureza, origem nacional ou social, riqueza, nascimento, ou qualquer outra condição. 2- Não será também feita nenhuma distinção fundada na condição política, jurídica ou internacional do país ou território a que pertença uma pessoa, quer se trate de um território independente, sob tutela, sem Governo próprio, quer sujeito a qualquer outra limitação de soberania.

Artigo $3^{0}$ Toda pessoa tem direito à vida, à liberdade e à segurança pessoal.

Artigo $4^{\circ}$ Ninguém será mantido em escravidão ou servidão; a escravidão e o tráfico de escravos serão proibidos em todas as suas formas.

Artigo $5^{\circ}$ Ninguém será submetido à tortu$\mathrm{ra}$, nem a tratamento ou castigo cruel, desumano ou degradante.

Artigo $6^{\circ}$ Todo ser humano tem o direito de ser, em todos os lugares, reconhecido como pessoa perante a lei.

Artigo $\mathbf{7}^{\circ}$ Todos são iguais perante a lei e têm direito, sem qualquer distinção, a igual proteção da lei. Todos têm direito a igual proteção contra qualquer discriminação que viole a presente Declaração e contra qualquer incitamento a tal discriminação.

Artigo $8^{\circ}$ Toda pessoa tem direito a receber dos tribunais nacionais competentes remédio efetivo para os atos que violem os direitos fundamentais quel he sejam reconhecidos pela constituição ou pela lei. 
Artigo $9^{\circ}$ Ninguém será arbitrariamente preso, detido ou exilado.

Artigo $10^{\circ}$ Toda pessoa tem direito, em plena igualdade, a uma justa e pública audiência por parte de um tribunal independente e imparcial, para decidir de seus direitos e deveres, ou do fundamento de qualquer acusação criminal contra ele.

Artigo $1^{\circ} 1$ - Toda pessoa acusada de um ato delituoso tem o direito de ser presumida inocente até que a sua culpabilidade tenha sido provada de acordo com a lei, em julgamento público no qual lhe tenham sido asseguradas todas as garantias necessárias à sua defesa. 2- Ninguém poderá ser culpado por qualquer ação ou omissão que, no momento, não constituíam delito perante o direito nacional ou internacional. Também não será imposta pena mais forte do que aquela que, no momento da prática, era aplicável ao ato delituoso.

Artigo $1^{\circ}$ Ninguém será sujeito a interferência na sua vida privada, na sua família, no seu lar ou na sua correspondência, nem a ataque à sua honra e reputação. Toda pessoa tem direito à proteção de lei contra tais interferências ou ataques.

Artigo $13^{\circ}$ 1- Toda pessoa tem direito à liberdade de locomoção e residência dentro das fronteiras de cada Estado. 2- Toda pessoa tem o direito de deixar qualquer país, inclusive o próprio, e a este regressar.

Artigo $14^{\circ} 1$ - Toda pessoa, vítima de perseguição, tem o direito de procurar e de gozar asilo em outros países. 2- Este direito não pode ser invocado em caso de perseguição legitimamente motivada por crimes de direito comum ou por atos contrários aos objetivos e princípios das Nações Unidas.

Artigo $1^{\circ} 1$ - Toda pessoa tem direito a uma nacionalidade. 2- Ninguém será arbitrariamente privado de sua nacionalidade, nem do direito de mudar de nacionalidade.

Artigo $\mathbf{1 6}^{\circ} 1$ - Os homens e mulheres de maior idade, sem qualquer restrição de raça, nacionalidade ou de religião, têm o direito de contrair matrimônio e fundar uma família. Gozam de iguais direitos ao casamento, sua duração e sua dissolução. 2- O casamento não será válido senão com o livre e pleno consentimento dos nubentes. 3- A família é o núcleo natural e fundamental da sociedade e tem direito à proteção da sociedade e do Estado.

Artigo $17^{\circ} 1$ - Toda pessoa tem direito à propriedade, só ou em sociedade com outros.2-Ninguém será arbitrariamente privado de sua propriedade.

Artigo $1^{\circ}$ Toda pessoa tem direito à liberdade de pensamento, consciência e religião; este direito inclui a liberdade de mudar de religião ou crença e a liberdade de manifestar essa religião ou crença, pelo ensino, pela prática, pelo culto e pela observância, isolada ou coletivamente, em público ou em particular.

Artigo $1^{\circ}$ Toda pessoa tem direito à liberdade de opinião e expressão; este direito inclui a liberdade de, sem interferência, ter opiniões e de procurar, receber e transmitir informações e idéias por quaisquer meios e independentemente de fronteiras.

Artigo 20" 1- Toda pessoa tem direito à liberdade de reunião e associação pacífica. 2- Ninguém pode ser obrigado a fazer parte de uma associação.

Artigo $21^{\circ}$ 1. Toda pessoa tem o direito de tomar parte no Governo de seu país diretamente ou por intermédio de representantes livremente escolhidos. 2. Toda pessoa tem igual direito de acesso ao serviço público do seu país. 3. A vontade do povo será a base da autoridade do Governo; esta vontade será expressa em eleições periódicas e legítimas, por sufrágio universal, por voto secreto ou processo equivalente que assegure a liberdade de voto.

Artigo $2^{\circ}$ Toda pessoa, como membro da sociedade, tem direito à segurança social, à realização pelo esforço nacional, pela cooperação internacional e de acordo com a organização e recursos de cada Estado, dos direitos econômicos, sociais e culturais indispensáveis à sua dignidade e ao livre desenvolvimento da sua personalidade.

Artigo $23^{\circ} 1$. Toda pessoa tem direito ao trabalho, à livre escolha de emprego, a condições justas e favoráveis de trabalho e à proteção contra o desemprego. 2. Toda pessoa, sem qualquer distinção, tem direito a igual remuneração por igual trabalho. 3. Toda pessoa que trabalha tem direito a uma remuneração justa e satisfatória, que lhe assegure, 
assim como à sua família, uma existência compatível com a dignidade humana, e a que se acrescentarão, se necessário, outros meios de proteção social. 4. Toda pessoa tem direito a organizar sindicatos e a neles ingressar para proteção de seus interesses.

Artigo $24^{\circ}$ Toda pessoa tem direito a repouso e lazer, inclusive a limitação razoável das horas de trabalho e a férias remuneradas periódicas.

Artigo $25^{\circ}$. Toda pessoa tem direito a um padrão de vida capaz de assegurar a si e a sua família saúde e bem-estar, inclusive alimentação, vestuário, habitação, cuidados médicos e os serviços sociais indispensáveis, e direito à segurança em caso de desemprego, doença, invalidez, viuvez, velhice ou outros casos de perda dos meios de subsistência em circunstâncias fora de seu controle. 2. A maternidade e a infância têm direito a cuidados e assistência especiais. Todas as crianças, nascidas dentro ou fora do matrimônio gozarão da mesma proteção social.

Artigo $26^{\circ} 1$. Toda pessoa tem direito à educação. A instrução será gratuita, pelo menos nos graus elementares e fundamentais. A instrução elementar será obrigatória. A instrução técnico-profissional será acessível a todos, bem como a instrução superior, esta baseada no mérito. 2 . A instrução será orientada no sentido do pleno desenvolvimento da personalidade humana e do fortalecimento do respeito pelos direitos do ser humano e pelas liberdades fundamentais. A instrução promoverá a compreensão, a tolerância e a amizade entre todas as nações e grupos raciais ou religiosos, e coadjuvará as atividades das Nações Unidas em prol da manutenção da paz. 3. Os pais têm prioridade de direito na escolha do gênero de instrução que será ministrada a seus filhos.

Artigo $27^{\circ}$ 1. Toda pessoa tem o direito de participar livremente da vida cultural da comunidade, de fruir as artes e participar do progresso científico e de seus benefícios. 2 . Toda pessoa tem direito à proteção dos interesses morais e materiais decorrentes de qualquer produção científica, literária ou artística da qual seja autor.

Artigo $28^{\circ}$ Toda pessoa tem direito a uma ordem social e internacional em que os direitos e liberdades estabelecidos na presente Declaração possam ser plenamente realisados.
Artigo $29^{\circ} 1$. Toda pessoa tem deveres para com a comunidade, na qual o livre e pleno desenvolvimento de sua personalidade é possível. 2. No exercício de seus direitos e liberdades, toda pessoa estará sujeita apenas às limitações determinadas pela lei, exclusivamente com o fim de assegurar o devido reconhecimento e respeito dos direitos e liberdades de outrem e de satisfazer as justas exigências da moral, da ordem pública e do bem-estar de uma sociedade democrática. 3. Esses direitos e liberdades não podem, em hipótese alguma, ser exercidos contrariamente aos objetivos e princípios das Nações Unidas.

Artigo $30^{\circ}$ Nenhuma disposição da presente Declaração pode ser interpretada como o reconhecimento a qualquer Estado, grupo ou pessoa, do direito de exercer qualquer atividade ou praticar qualquer ato destinado à destruição de quaisquer dos direitos e liberdades aqui estabelecidos.

Assembléia Geral da Organização das Nações Unidas, 10 de dezembro de 1948 